leave regulations, career guidance, advising the health authority on educational matters, and so on. The material reward is a yearly honorarium of $£ 1300$. Many colleagues, who would probably be excellent tutors, decline the task. I doubt whether the small emolument is the reason, but it does suggest that the job is not valued highly in some quarters.

I share Dr Paton's anxiety about the low priority given to postgraduate education in district and regional planning. A major hospital development in this health district is nearing completion without any facility for postgraduate medical education in spite of local observations that our existing centre is too small and will need to be replaced within 10 years. There seems to be a reluctance, even among medical administrators, to accept that it is actually in the interests of patients for those who look after them to pursue postgraduate education by research, attending courses or conferences. All too often the doctor is made to feel guilty if he or she applies for study leave, and most rarely, if ever, do so. Many consultants are unaware of their study leave entitlement, and when they do find out about it they discover that rights are not retrospective and that they may not have accrued leave for their years of service. I hope that the coming of medical audit with peer review will lead to a more enlightened attitude to continuing education. Study leave, covered by locums, should become the rule rather than the exception.

In the 25 years since the Christ Church conference postgraduate medical education has established a foothold in each health district. Perhaps in the next quarter of a century we shall ensure that medical education really does continue throughout a doctor's life, as Sir William Osler insisted it should 100 years ago.

Shorwell

Isle of Wight PO30 3JZ

DAvid W HIDE

SIR,-Dr Alex Paton's review (14 February, $p$ 393) of continuing medical education 25 years on-" the complexity, confusion, and uncertainty"-makes rather sombre reading. The early chairmen of the Council for Postgraduate Medical Education strove to keep it small and reasonably effective, but to no avail. Hence today's "complex educational bureaucracy ... . deferring to vested interests and rigid requirements for training."

As I am sure Dr Paton would agree, however, one solid and enduring outcome of the Christ Church conference is the existence of a working medical library at the heart of every district medical centre, funded largely by the then regional hospital boards. The library was a particular yardstick, which Sir George Pickering himself would apply when appraising any place of learning, and this development throughout the National Health Service is a fitting tribute to his lively concern for genuine and continuing education. It is difficult to appreciate that 20 years ago this basic tool simply did not exist in so many hospitals where it is now taken for granted.

A W WILliams

Marlesford,

Suffolk IP13 0AT

\section{Doppler studies in the growth retarded fetus}

SIR,-We would like to make two points about the paper by Dr G A Hackett and others (3 January, p 13), which showed an association between absent end diastolic flow in the fetal aorta in growth retarded fetuses and poor neonatal outcome.

The suggestion that this pattern predicts specifically complications for the neonate is not really substantiated by the study. The higher rate of complications in group 1 (absent end diastolic flow) reflects a subgroup with severe growth retardation, which is associated with abnormal flow, but this subgroup is in any case at greater risk of necrotising enterocolitis, haemorrhage, and neonatal morbidity.

The statement that the gestational age in the two groups was similar is difficult to assess withou knowing the distribution of gestational age in the groups. If the gestational ages were not distributed normally non-parametric statistical tests would have been more appropriate.

M J WhITTLE K P HANRETTY

Queen Mother's Hospital

Glaengow G3 8SH

AUTHORS' REPLY - Firstly, with regard to Drs M J Whittle's and K P Hanretty's statistical query, we found that the gestational ages in both groups followed a Gaussian distribution, which justified parametric analysis.

Secondly, we agree that the group of fetuses with abnormal aortic blood flow was the more retarded in growth. As we stated in our paper, however, other clinical variables, including an ultrasonic estimation of a birth weight below the 5th centile, did not prove as sensitive as the loss of aortic end diastolic frequencies in the prediction of neonatal complications. Even severe intrauterine growth retardation is not always associated with impaired placental transfer, and only a minority of such fetuses suffer antenatal hypoxia. ${ }^{1}$ We have shown an inverse correlation between the mean aortic blood velocity and the degree of antenatal fetal hypoxia in fetuses with intrauterine growth retardation $^{2}$ and more recently found an inverse correlation between blood velocities in the aorta and the common carotid artery in a similar group of fetuses.

It seems logical that methods of measuring the redistribution of the fetal circulation in response to hypoxia should be better predictors of necrotising enterocolitis, haemorrhage, and other neonatal complications than techniques that measure fetal size alone.

G A HACKETT S CAMPBELI

K H NiCOLAIDES C BILARDO

Department of Obstetrics and Gynaecology,

King's College School of Medicine and Dentistry,

London SE5 8RX

Soothill PW, Nicolaides KH, Bilardo CM, Campbell S. Relation of fetal hypoxia in growth retardation to mean blood velocity in the fetal aorta. Lancet 1986;ii:1118-9.

2 Soothill PW, Nicolaides KH, Campbell S. Prenatal asphyxia, hyperlactaemia, hypoglycaemia, and erythroblastosis in growth retarded fetuses. B Med f (in press).

\section{Simple analgesics in pregnancy}

SIR,-Dr C W Howden's reply to Dr T Steiner (31 January, p 308) seems to confuse the issue still further. If we compare the data on any drug that has been studied extensively with those on one that has not and find that in neither case has anything significant been shown then we cannot conclude that it is the "lack of positive data on" one "which is so significant" when that one is the less studied member of the pair.

Statistical analysis tells us not that something is true or false but the likelihood that the finding could be of no significance because it might have arisen by chance alone. More studies increase the risk of such a mischance, every extra study increasing the chance of a spurious but apparently significant result turning up. The more extensively a drug is studied the more likely it is that an apparently adverse finding will be published.

When findings have more than a $5 \%$ likelihood of being chance events they are widely accepted as being "not significant"; indeed the $5 \%$ figure is theoretical and will generally be an underestimate because imperfect matching of the two groups studied or an unrecognised systematic variable will lead to more spurious differences being found. How much more should caution apply to the interpretation of data that are declared by their author not to be significant. Isn't such a misanalysis the basis of Dr Howden's reply?

GORDON R FRYERS

Woodhurst Park,

Oxted RH8 9HA

\section{Corticosteroids and bone mass in asthma}

SIR,-It is unusual to see detailed and informed criticism of a paper such as that by Dr D M Reid and others (6 December, p 1463) from an authority as eminent as Dr Graham K Crompton (10 January, p 123) without the benefit of a response from the original authors. The authors should either rebut Dr Crompton's points or retract their article. People casting doubt on important established therapeutic practice have a special responsibility to make their facts clear and their speculation distinct so that standard therapeutic practice is not unjustifiably undermined.

G J ADDIS

Department of Materia Medica

Stobhill General Hospital,

Glasgow G21 3UW

\section{Dialysis arthropathy: amyloid or iron?}

SIR,-The purpose of our paper (29 November, $p$ 1392) was to report that there were conspicuous deposits of iron in synovial biopsy specimens from patients with dialysis arthropathy as well as amyloid. Previous reports of synovial biopsies in such patients have not mentioned this finding. As Dr P Hardouin and colleagues suggest (24 January, p 246), synovial iron deposits may well be a rather non-specific feature of a variety of joint diseases. Nevertheless, recent work supports the notion that iron catalysed oxidative reactions can influence synovial inflammation. ${ }^{1}$ The conspicuous deposits of iron present in the synovial tissue of the patient with dialysis arthropathy that we described were thought to be the result of repeated haemarthrosis, though we did not discount the possibility that at least some of them could be a manifestation of iron overload.

Our experience of juxta-articular bone cysts in patients who undergo haemodialysis is also that these are filled with amyloid that stains positively for $\beta_{2}$ microglobulin. At least some of these, however, may be the result of past or present secondary hyperparathyroidism or detritus cysts associated with osteoarthrosis. Amyloid may then simply fill the space and not destroy bone as $\mathrm{Dr}$ Hardouin and colleagues suggest.

The roles of $\beta_{2}$ microglobulin and amyloid in the pathophysiology of dialysis arthropathy remain unclear. Serum $\beta_{2}$ microglobulin tends to reach high concentrations in the first four years of haemodialysis using cuprophane membranes, ${ }^{2}$ but dialysis arthropathy is rarely seen until much later. The amelioration of joint symptoms referred to by Dr Hardouin and colleagues after a change of dialysis membrane suggests that amyloid is also not directly connected with the pathogenesis of symptoms. 
With regard to the comments of Dr R Ahmad and coworkers (7 February, p 372) it is interesting that their patients undergoing carpal tunnel release did not have arthropathy affecting large joints. This suggests that the carpal tunnel syndrome, though often seen in association with the arthropathy that affects large joints, may have a different pathogenesis. It is therefore perhaps not surprising that synovial iron deposits were rare in their patients. Amyloid deposits may be a factor in the carpal tunnel syndromes, and some patients with amyloidosis associated with plasma cell dyscrasias are known to develop this complication. ${ }^{3}$

N R B CARY

D SETHI

EDWINA ANNE BROWN

C C ERHARDT

D F WOODROW P E GOWER

Department of Histopathology,

Charing Cross and Westminster

Medical School,

London W6 8RF

I Winyard PG, Blake DR, Chirico S, Gutteridge JMC, Lunec J. Mechanism of exacerbation of rheumatoid synovitis by total dose iron-dextran infusion: in-vivo demonstration of iron promoted oxidant stress. Lancet 1987; ;:69-72.

2 Sethi D, Gower PE. Dialysis arthropathy, $\beta-2$ microglobulin levels and the effect of the dialyser membrane. Clin Sci 1987;72:67-8.

3 Wiernik PH. Amyloid joint disease. Medicine 1972;51:565-79.

\section{Empirical evidence and authoritarian ethicists}

SIR,-Dr Iain Chalmers's letter (24 January, p 247) is a perfect example of the way in which some doctors accept lower academic standards for ethical than for scientific matters.

Dr Chalmers has spent years in promoting the proper scientific study of various perinatal issues and in criticising those research projects that he considers not to have been correctly performed or interpreted. As soon as I question a couple of points about a comparison of two ways to obtain informed consent, however, he becomes sad at my attempt to "discredit" the comparison, apparently because the comparison was one of a "vanishingly small" number of studies collecting empirical evidence about the information needed for consent. He goes on, however, to mention a review of such empirical evidence recently published by IME Bulletin, ${ }^{1}$ which considers 30 studies on this subject. Were Dr Chalmers to review 30 studies in one particular area of perinatal epidemiology I suspect that he might complain that the subject had been overresearched, rather than saying the number was "vanishingly small." Dr Chalmers next criticises me for not endorsing the call of the review's author for more research. One of my editorial changes to Dr King's published paper was to draw attention clearly to the problems for which more research is needed.

At the Institute of Medical Ethics we are trying to promote high academic standards in the study of medical ethics. If that requires the questioning of the validity of empirical studies then such questioning will continue. And, to revert to my criticism that prompted Dr Chalmers's letter, I do still find it pretty odd to enter patients into a trial without their knowledge or consent in order to assess the extent to which one should respect their autonomy.

R H NichOLSON

IME Bulletin,

London W1N 5PB

1 King J. Informed consent. IME Bulletin 1986;suppl No 3.

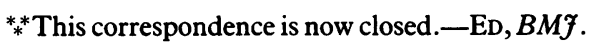

\section{Poverty and teenage pregnancy}

SIR,-Susan Williams and colleagues have shown the importance of poverty among teenage mothers in the east end of Glasgow (3 January, p 20) and conclude that social inequalities do not seem to have reduced and that inequalities in health will persist as long as such disadvantage continues. We have further evidence of this trend in the results from two national samples of births in France in 1972 (11 254 births) and 1981 (5508 births).

In both 1972 and 1981 pregnant women aged under 20 were significantly underprivileged compared with older women. ${ }^{2}$ Moreover, the social circumstances of teenagers deteriorated during these 10 years: the proportion of pregnant women aged under 20 who were not living with their child's father was $11 \%$ in 1972 and $18 \%$ in 1981 , and the proportion of those who were unemployed during pregnancy increased from $42 \%$ to $72 \%$. The relative "marginalisation" of pregnant women aged under 20 may result not only from the economic crisis but also from the unequal distribution of reliable means of birth control. In 1972 very few were available in France; by 1981 the pill was covered by national insurance and available to minors without parental consent, and termination of pregnancy was legal. Nevertheless, access to effective contraception or legal abortion remained very difficult for economically and socially underprivileged women.

During these 10 years the take up of antenatal care increased among all pregnant women, whatever their age, but in 1981 the proportion of women who had fewer than four antenatal visits remained higher among women aged under 20 than among other women. In 1981 the preterm delivery rate was $10.5 \%$ among women aged under 20 , very similar to the rate observed in 1972 , and $5.3 \%$ among older women $(8.0 \%$ in 1972$)$. The relative risk of preterm delivery in young women increased from 1.4 in 1972 to $2 \cdot 1$ in 1981 .

The number of teenage pregnant women is decreasing, but the results show that they still need special support, financial help, and medical care.

BÉATRICE BLONDEL MONIQUE KAMINSKI MARIE-JosèPHe SAÚREL-CuBIZOLLES Unité de Recherches Epidemiologiques sur la Mère et l'Enfant, 94807 Villejuif,

France

1 Rumeau-Rouquette C, du Mazaubrun C, Rabarison Y. Naitre France. Dix ans d'évolution. Paris: INSERM-Doin, 1984.

2 Bondel B, Kaminski M, Saurel-Cubizolles M-J, Bréart G. Pregnancy outcome and social condition of women under 20. Int $\mathcal{f}$ Epidemiol (in press)

\section{Depression and outcome in acute myocardial infarction}

SIR,-Dr P H Silverstone writes "Clearly, depression in the first 24 hours after myocardial infarction represents a considerably increased risk of early death..." (24 January, p 219). The interactions between mental state and the various manifestations of coronary artery disease are interesting but far from clear, and although Dr Silverstone shows an association between depression and impending death, it is difficult to be sure which is cause and which effect. Aware of this dilemma, Dr Silverstone gives spot measurements of enzyme activities as evidence of similarity of infarct size in the survivors and non-survivors. The mean aspartate transaminase activity in one group was given as $202 \mathrm{IU} / 1$, with a standard deviation of 378 , which illustrates one of the pitfalls associated with the presentation of non-Gaussian data and casts suspicion on the statistical inference drawn. Spo assays are for diagnosis and relate poorly to infarct size, and in any case survival depends on how much cardiac function remains.

Psychiatric measurements must also be used properly. The Montgomery-Asberg rating scale was not designed for use in a coronary care unit, within 24 hours of infarction, and may not be robust enough to withstand these circumstances. Surely the simplest explanation for the relation between mood and death is that the iower your cardiac output the worse you feel and the worse you do?

Institute of Psychiatry,

JANET TREASURE

London SE5 8AF

Middlesex Hospital,

TOM TREASURE

Middlesex Hospital
London W1N 8AA

AUTHOR's REPLY,-Dr Janet and $\mathrm{Mr}$ Tom Treasure raise an interesting point regarding my original article-namely, whether the depression I describe was simply a manifestation of more severe disease. Unfortunately, I was limited by space and could not give the information they require. Firstly, the enzyme activities were in fact the highest reached in a series of four assays done on consecutive days. Enzyme activities have been shown to relate well to infarct size, but usually with creatine phosphokinase rather than aspartate aminotransferase. ${ }^{1}$ At the hospital where this study was carried out assays for creatine phosphokinase were not available until the end of the study. The last 15 patients underwent creatine phosphokinase assays, which correlated with the aspartate aminotransferase and lactate dehydrogenase results.

There were no electrocardiographic indications that the infarcts were larger in the groups with depression and no changes on continuous cardiac monitoring or in the incidence of congestive failure, which correlate with early death. ${ }^{23}$ The Montgomery-Asberg rating scale was designed to be sensitive to change, specifically for research purposes. Measurements were taken with this scale on the first day and on successive days until discharge. The patients' rating scale scores declined over this period, so that at seven days $30 \%$ of the surviving patients were depressed. This result is very similar to those of previous studies that have looked at depression in patients after infarction using other rating scales. ${ }^{4}$

In another study I looked at patients with acute first subarachnoid haemorrhage, acute gastrointestinal bleeding, and pulmonary embolism. In all of these groups the same relation was shownnamely, that patients with equivalent lesions who are depressed do far worse than those who are not, and that $40-50 \%$ of patients who are admitted acutely are depressed, as measured by the Montgomery-Asberg scale.

All studies of depression in the physically ill have the same difficulty in the use of rating scales. For example, poor appetite, difficulty in sleeping, and lethargy may well be due to the underlying physical problem. It is for this reason that the cut off for depression in this study was set higher than normal.

The answer to the question "Don't you feel worse because you are worse and therefore you do worse?" is that in a range of life threatening illnesses patients who are no worse but feel worse do worse.

London SW9

Peter Silverstone

1 Geltman EM, Ehsani AA, Campbell MK, et al. The influence of location and extent of myocardial infarction on long term ventricular dysrhythmia and mortality. Circulation 1980;62 960

2 Moss AJ, Paris HT, DeCamilla J, Bayer LW. Ventricular ectopic beats and their relation to sudden and non-sudden cardiac death after myocardial infarction. Circulation 1979;60:998. 